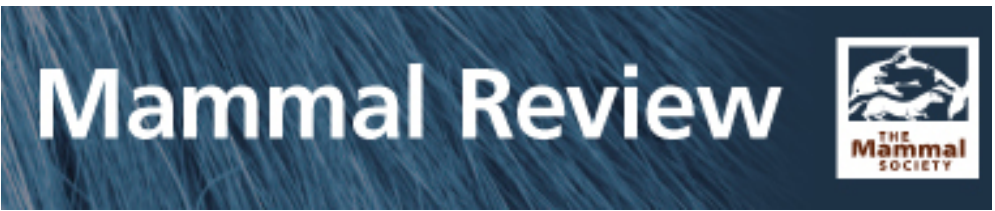

\title{
Current status of American mink in Britain: a review of the evidence for a national-scale population decline
}

\begin{tabular}{|c|c|}
\hline Journal: & Mammal Review \\
\hline Manuscript ID & MAMMAL-19-30.R2 \\
\hline Manuscript Type: & Invited review \\
\hline $\begin{array}{r}\text { Please provide one keyword } \\
\text { (or phrase) describing the } \\
\text { taxon or taxa covered by the } \\
\text { study (e.g. Carnivores, } \\
\text { Rodents, rats, Rattus rattus, } \\
\text { livestock, bats, wolves and } \\
\text { prey, etc.): }\end{array}$ & $\operatorname{mink}$ \\
\hline $\begin{array}{r}\text { Please provide one keyword } \\
\text { (or phrase) on the } \\
\text { geographical area covered by } \\
\text { the study (e.g. global, } \\
\text { Europe, British Isles, N } \\
\text { America, Northern } \\
\text { Hemisphere, etc.): }\end{array}$ & British Isles \\
\hline Keywords : & $\begin{array}{l}\text { monitoring, scat surveys, marking behaviour, intra-guild competition, } \\
\text { invasive species control }\end{array}$ \\
\hline Subject Areas (select one): & Conservation/management \\
\hline $\begin{array}{r}\text { Mammalian Orders (select all } \\
\text { that apply): }\end{array}$ & Carnivora \\
\hline
\end{tabular}

\section{SCHOLARONE \\ Manuscripts}


Invited Review

Current status of American mink in Britain: a review of the evidence for a national-scale population decline

Abstract

1. American mink in Britain are an invasive alien species, with significant impacts on native prey species. There have been suggestions that mink in Britain have declined since the 1990s.

2. Three nationwide datasets include data on mink distribution and abundance. Scat surveys and the National Game Bag Census suggest population declines, but the latter does not take account of survey effort (which may also have declined) and the former is misleading because there is evidence that mink change their marking behaviour in the presence of otters. National Biodiversity Network data suggest an increase in mink numbers but this can be explained by a concomitant increase in mammal recording.

3. Although intra-guild competition between invasive mink and native otters is likely, there is no evidence that otters have caused a decline in mink numbers. There is little information on the impact of disease, or exposure to rodenticides, on wild mink - both warrant further attention. Culling can have an impact on mink populations, but currently neither implementation nor monitoring is sufficient to generate national-level effects or to assess the national-level impact of cumulative local efforts. 
4. We conclude that, at a national level, it is not possible, on the basis of currently available data, to ascertain the current status of mink or assess the underlying trend in their population. We stress the importance of collaboration, coordination, and record keeping (and sharing) in future, proper interpretation of existing data, and the use of alternative data sources. We call for greater, and better, effort in both mink management and monitoring of management in Britain.

Key words: monitoring, scat surveys, marking behaviour, intra-guild competition, invasive species control

\section{Introduction}

Non-native American mink Neovison vison (hereafter mink) are considered to be one of the most damaging invasive species in Europe (Nentwig et al. 2018): highly adaptable, generalist predators (Dunstone 1993) that have serious impacts on the populations of 47 native prey and on competitor species (Genovesi et al. 2012). In Britain, mink predation is responsible for declines in the populations of water voles Arvicola amphibius (formerly A. terrestris, Moorhouse et al. 2015) and ground-nesting seabirds (Craik 1997). There have been suggestions (e.g. Bonesi et al. 2006) that over the last two or three decades the number of mink in Britain has declined. However, there has been no recent published assessment of the species' status at a national level. The purpose of this review was to critically evaluate the data currently available for such an assessment. In so doing, we also consider the possible role of four factors - intra-guild competition, disease, rodenticides, and culling that may be (or have been hypothesized to be) associated with a potential decline in mink 
populations. First, to provide context, we give a brief overview of the colonization of Britain by mink (including concomitant changes in the native predator guild), and a summary of the early evidence for a decline in their British population.

\section{Mink in Britain}

Originally transported by people for fur farming, escapes and, in some cases, deliberate releases from farms have resulted in established populations of mink in most European countries (Macdonald and Harrington 2003). The first British mink farm opened in England in 1929; by the peak of the UK fur trade, in the early 1960s, there were at least 600 mink farms in Britain (Thompson 1968, Cuthbert 1973). Mink were first recorded breeding in the wild in South West England in 1956 (Linn and Stevenson 1980), but spread in England, Scotland and Wales, through the 1960s, in a number of discrete areas centred around mink farms (Thompson 1968, Cuthbert 1973, Fraser et al. 2017). Having colonized an area, local occupancy continued to increase over the following decades - albeit at different times in different regions - such that, for example, having first appeared in the Upper Thames valley, in South East England, in the early 1960s, signs only became numerous during the 1980s (Strachan and Jefferies 1993). Across 161 survey sites throughout the region (each a 600m stretch of river bank), mink occupancy increased from 7\% in 1975, to $25 \%$ in 1990 (although all mink farms in the catchment had closed by the late 1980s), reaching $46 \%$ by 1995 (Macdonald et al. 2015), and continuing to spread into the upper reaches of the catchment by the early 2000s (Harrington et al. 2009a). 
Mink are semi-aquatic and, in Britain, inhabit riparian strips of coastal and freshwater habitats, preferring sheltered rocky shore on the coast (Bonesi et al. 2000), and tree, scrub and grass cover in riverine areas (e.g. Yamaguchi et al. 2003). Resident adult males occupy linear home ranges (of c. $1-9 \mathrm{~km}$ ) along waterways (usually within $10 \mathrm{~m}$ of the water's edge) that overlap one to three smaller $(<1-4 \mathrm{~km})$ female home ranges (Dunstone 1993, Macdonald et al. 2015). Both sexes are solitary and territorial, albeit with some home range overlap both within and between sexes (Macdonald et al. 2015 and references therein). Densities are dependent on habitat (Dunstone 1993) and resources (e.g. Melero et al. 2014). In southern England, summer (resident) densities were between $0.4-0.9$ mink per km (Harrington et al. 2009b), increasing seasonally due to an influx of transient males during the mating season (January - March) and juveniles during the dispersal season (August September). On inland streams and lochs on the Outer Hebridean islands, densities might be as low as 0.2 mink per km but more than 1 per $\mathrm{km}$ on the rocky shoreline (Moore et al. 2003).

By the early 2000s, there were fewer than 20 mink farms in England and Wales, the last of which was closed in 2002, under the Fur Farming (Prohibition) Act 2000 (www.legislation.gov.uk), which came into effect on January 1 2003. In Scotland, the last mink farm closed in 1993, and fur farming was prohibited by the Fur Farming (Prohibition) (Scotland) Act 2002. By this time, feral mink were widespread in all regions in England (Crawford 2003), much of Wales, and all except the far north of Scotland (Strachan 2007). Mink continue to spread into the northern highlands (Harrington et al. 2010), primarily by moving along the coast (Fraser et al. 2017). Mink also occur on offshore islands that are within swimming distance of the mainland (e.g. Craik 2008), but are believed to have been 
successfully eradicated from the Outer Hebridean islands (SNH 2018). Throughout their

British range, mink are subject to population control albeit in a patchy and largely uncoordinated manner - the impact of culling is discussed further below.

Mink colonized Britain at a time when two native competitors - otters Lutra lutra (that at c. $6-10 \mathrm{~kg}$ are much larger than a $1 \mathrm{~kg}$ mink) and polecats Mustela putorius (also c. $1 \mathrm{~kg}$ ) were absent from much of the country. Otters had suffered substantial population declines due to aquatic pollution resulting from widespread use of organochlorine insecticides in the 1950s (possibly accentuated by a long history of over-hunting, Strachan and Jefferies 1996), whilst polecats had been heavily persecuted by gamekeepers in the late nineteenth century (Birks and Kitchener 1999). In the 1960s, polecats were largely confined to Wales (Corbet 1971) and otters were declining (almost to extinction in England, but to a lesser extent in Scotland, Chanin and Jefferies 1978; Sainsbury et al. 2019 and references therein). Some authors posited that this situation may have facilitated the spread of mink (e.g. Chanin and Jefferies 1978; see also Ruiz-Olmo et al. 1997, Rodrigues et al. 2015). However, mink also successfully colonized regions of Scotland where otters remained widespread (Fraser et al. 2017; discussed further below). Both otters and polecats have now recovered in Britain (Croose 2016, Crawford 2010) as a result of improved water quality and reduced culling, respectively. Otters are now found across Britain, albeit patchily in the South East (Crawford 2010). Polecats have spread into central, eastern and southern England, although they have not yet recolonized parts of northern England or Scotland (Croose 2016). In Belarus, American mink out-compete female polecats and exclude them from aquatic habitats (Sidorovich et al. 1999), and, across their European range, the proportion of reproductive females in the polecat population is lower where they co-occur with mink 
119 (Barrientos 2015). There is no evidence that the UK recovery of polecats has been hindered

120 by the presence of mink (see e.g. Sainsbury et al. 2019), probably because in the UK

121 polecats are similar in size or slightly larger than mink (Harrington and Macdonald 2008),

122 whereas in Belarus they are smaller (Sidorovich et al. 1999). Inter-specific interactions

123 between otters and mink are discussed further below.

124

125 Early evidence of a decline in mink in Britain

126

127 Analyses by Jefferies (2003) provided the first evidence of a wide-scale mink decline in

128 Britain. Using data from mammal atlases and national otter and water vole surveys (the

129 latter based on the detection of mink field signs, predominantly scats), country-wide occupancy of surveyed hectads ( $10 \times 10 \mathrm{~km}$ survey squares) appeared to decline through the 1990s. The timing of the decline, however, differed regionally such that between the 19891990 water vole survey and the 1991 - 1994 otter survey the proportion of hectads occupied by mink in Western England declined (from $72 \%$ to $66 \%$ ), whereas it continued to increase in Eastern England (from 59\% to 66\%). By the 1996- 1998 water vole survey, mink occupancy had declined (to approximately $30 \%$ ) in each of Western and Eastern England, and Scotland, and to $11 \%$ in Wales (Fig 1; note that this broad-scale analysis does not preclude different patterns of increase/decrease within hectads, such as, for example, observed in the Upper Thames through the 1990s). These regional differences were cooccurred with the pattern of otter recovery, which started earlier in the west, leading to the suggestion that otters a key driver of mink decline (see also Strachan and Jefferies 1996), but more recent work does not support this hypothesis (discussed further below). 
[INSERT FIG 1]

144

145

\section{Nationwide data available}

146

147 Three independent data sources include national-level information on mink distribution and/or abundance in Britain: 1) national surveys for otter and water vole, run by the Environment Agency (www.gov.uk/government/organisations/environment-agency), and the Vincent Wildlife Trust, respectively; 2) the National Game Bag Census run by the Game and Wildlife Conservation Trust (www.gwct.org.uk); and, 3) National Biodiversity Network data (nbn.org.uk/). Each of these datasets has its own strengths but each also suffers weaknesses that limit the inferences that can be drawn from it. We excluded local mink control projects as a fourth dataset because coverage is currently patchy and inconsistent. In England, fewer than half of counties (at the time of writing) had a mink control project, and, of 10 English projects, only two were county-wide (most operated at a single site). In Scotland, a large landscape-scale study has been informative in terms of demonstrating the potential impact of culling on mink populations (discussed further below) but it does not (currently) provide countrywide monitoring data.

National otter and water vole surveys

Although mink were never the primary focus of these surveys, their presence throughout Britain has been tracked, since the 1970s, alongside the changing distribution and abundance of these two native species that share their riparian habitat (Jefferies 2003 and earlier surveys cited therein, Crawford 2003, 2010, Strachan 2007). These surveys record 
167

168

169

170

171

172

173

174

175

176

177

178

179

180

181

182

183

184

185

186

187

188

189

190

presence of mink on the basis of detected field signs (predominantly scats) - they are

standardized, repeatable, and, because they collect data on more than one species

simultaneously, they are efficient. Here we confine our analysis to the otter surveys of

England, which include the most complete and up-to-date information for mink, in part

because otter surveys in Scotland no longer record mink, and there has been no national

water vole survey since 1998. These data show that although mink were still found in every

region of the country in the 2009-2010 survey, there was a further decline in the proportion

of mink-positive hectads between 2000-2002 and 2009-2010 (Crawford 2010), suggesting

an overall loss of 32\% of occupied hectads since the 1991-1994 survey (Fig 2). At the level of individual $600 \mathrm{~m}$ survey sites, the proportion of mink positive sites in England had declined from $21.9 \%$ ( 728 of 3,327 surveyed) in $2000-2002$, to $15 \%$ (510) in $2009-2010$.

\section{[INSERT FIG 2]}

There are two weaknesses inherent in these data. First, due to resource constraints in both recent (2000-02 and 2009-10) surveys, searches for signs ceased once otter signs were found, so the greater the presence of otters, the greater the risk of false negatives for mink (survey bias). Bonesi et al. (2006) corrected for this effect and suggested that unbiased declines had occurred in the percentage of sites occupied between the 1977-79 survey and the 2000-02 survey in 19 of $3250 \times 50 \mathrm{~km}$ squares surveyed. Further, these authors suggested that the percentage of sites within a $50 \times 50 \mathrm{~km}$ square that appeared to gain or lose mink was significantly correlated with the relative density of otters. The second weakness in these data is that this conclusion is based on the assumption that mink signs are equally detectable across survey sites with varying otter presence. A study on the River 
191 Cherwell in the Upper Thames valley in 2004-2005, documenting the presence of both otters and mink (based on scats and footprints on mink monitoring rafts), provides some evidence that this is not the case and suggests that mink, in the presence of otters, reduce or change their marking behaviour (Harrington and Macdonald 2015). Field signs and extensive surveys by the local Wildlife Trust suggested that otters had colonised the River Cherwell in the summer/autumn of 2004. Concurrent with this event, the proportion of

$197(500 \mathrm{~m})$ river sections in which mink scat was detected declined, whilst the proportion of rafts with mink tracks increased (Fig 3). Thereafter, the use of rafts by mink remained high and scat detection remained low (Fig 3). The number of individual mink present during this time period was not known, so it is possible that mink numbers did not change, but that those present moved over increasingly larger areas (leaving tracks over more rafts). Mink density the following year (2005-2006), however, at 0.5-0.8 mink per km (and after the apparent decline), was comparable to that on other rivers in lowland England in the absence of otters (see Harrington and Macdonald 2015 and references therein), suggesting that a decline in the level of marking by mink is a more parsimonious explanation than a decline in their numbers. Further, a total of 84 scats were counted in the entire $20 \mathrm{~km}$ survey site in the first survey in July 2004, whilst fewer than 20 scats were counted in all seasonal surveys after the arrival of otters, which was similar to that found on other otter-occupied rivers within the Thames catchment (unpub. data). Other species alter their marking behaviour to avoid detection by competitors: laboratory mice reduce their marking activity in the presence of predator odour (Roberts et al. 2001) and lone dispersing wolves do not scent mark (Rothman and Mech 1979). If this is true of mink, any decline in mink inferred on the basis of a decline in detection of their scats in the presence of otters is potentially flawed. 
An additional weakness associated with field sign surveys (for any species) is the risk of species misidentification, which can be high even among expert surveyors (e.g. Harrington et al. 2010, Birks et al. 2004). Certainly, throughout Britain, the polecat's expanding range is likely to confound identification of mink signs because the scats and prints of the two are so similar (Harrington et al. 2008) - for example, a reported 200\% increase in hectads occupied by mink in the Wye Region (where polecats are abundant), in the 2009-2010 otter survey, is suspicious. This argument is not relevant at a countrywide scale because an increase in mink field signs has not been observed over a larger area; however, it serves to illustrate the point that inferences from scats should always be drawn with caution.

National Game Bag data

Insofar as game bag data provide direct counts of individual animals (albeit dead ones), the strengths of these data are that they are easier to interpret than scat surveys and potentially more reliable as an indicator of population size. The GWCT's National Game Bag Census (NGC) comprises trapping records from 530 shooting estates throughout the UK since 1962. These data show a significant decline in the game bag index for mink since 1978, and a 41\% countrywide decline (95\% Cl: 33 - 49\%, Fig 4) in the numbers killed between 1995 and 2009 (Aebischer et al. 2011). The weakness of this dataset is that it does not include data on, nor take account of, trapping effort, so the possibility that the decline observed is entirely due to a reduction in effort (see e.g. McDonald and Harris 2001) cannot be ruled out. Although the number of gamekeepers working on each estate is recorded, and thus 
could be accounted for, the number of days spent trapping and the number of traps set is not.

National Biodiversity Network records

The national biodiversity network (NBN) is a collaborative, partnership organisation responsible for collating and sharing biological information (nbn.org.uk/about-us/who-weare/), much of which comes from volunteers and sighting reports from members of the public, submitted via the Local Environmental Records Centres. The strength of this dataset is its size: currently it holds over 200 million records, including 14,000 records of mink presence spanning seven decades. Data from England, Wales and Scotland all show a clear increase in the number of mink records since the 1990s (Fig 5a-c), contradicting other sources of evidence that suggest a recent decline. The weakness in these ad hoc biological records is that they are subject to bias due to uneven sampling and detection (Isaac and Pocock 2015), and thus show trends in recording effort (including citizen involvement) in addition to any underlying trends in numbers. A map of mink records in 2010 , for example, clearly depicts recording effort centred around local control projects (Fig $5 \mathrm{~d}$ ) and almost certainly does not reflect mink abundance. 
264 Until 1978, when otters were protected in England and Wales under the Conservation of

265 Wild Creatures and Wild Plants Act, hunting otters with dogs for sport was a traditional

266 English pastime (Chanin 2013). Following the protection of otters, some otter hound packs

267 switched to hunting mink (Dunstone 1993). Hunting is carried out from April to September

268 and proceeds by the dogs searching the river bank and 'flushing' mink from any dens found.

The number of mink encountered, and the number killed, over the years' hunting season, are recorded and divided by the number of days hunted to provide a standardized indicator of mink numbers that is corrected for effort (unlike those of the NGC). These data held by local mink hound packs are the most unbiased data currently available. Recent data from the mink hound pack in Devon and Cornwall indicate a steady decline in both indices since 1996 (Fig 6). The pack last hunted in 2015, during which they hunted on 35 days (within the rules and exemptions of the Hunting Act 2004, M. Prout, pers. comm.), covering an average of $6 \mathrm{~km}$ per day, and failed to find any mink (M. Prout, pers. comm.), suggesting that mink, at least in this region, have undergone a true decline.

[INSERT FIG 6]

\section{What factors might cause a decline in mink populations?}

Intra-guild competition

The intraguild hypothesis was proposed by Bonesi and Macdonald (2004), who 
287 occupied) and in the numbers of mink trapped (from nine to four per 1000 trap-nights)

288 following the release of otters in the Upper Thames valley in 1999. These authors suggested

289 that otters caused the decline in mink by direct aggressive interference competition and

290 that, in the presence of otters, mink densities would be reduced by about half. That

291 aggressive interactions between the two species does occur was supported by Simpson's

292 (2006) finding of road-killed otters with facial bite wounds that seemed to have been caused

293 by mink (a lack of comparable bite-wounded mink suggests that mink do not survive such encounters, V. Simpson, pers. comm.).

Here, we have argued that a decline in the occurrence of scats is most likely due to predator-induced changes in marking behavior. In addition, the reported change in the number of mink trapped in Bonesi and Macdonald's (2004) experiment was within the range of seasonal and inter-annual variation observed elsewhere (cf. Harrington et al. 2009a). Further, five years later at the same site, when otters were well-established in the area, mink (as evidenced by footprints recorded on mink rafts, and live trapping) were still abundant, and there was no evidence of a decline in their numbers (adult summer population $=9.3 \pm 3.2$ mink in 1995 , compared with $12.6 \pm 2.3$ in 2005, Harrington et al. 2009b). Indeed, although there is some evidence of temporal avoidance (Harrington et al. 2009b), otters and mink have been observed to repeatedly use the same mink rafts on the same nights (D. Tansley, pers. obs.) and, elsewhere, mink and otters coexist on the same rivers (e.g. in Spain, Podrá and Gómez 2018, and Belarus, Sidorovich and Macdonald 2001). no evidence (or, indeed, biological basis) for the exclusion of mink by otters, or of intra-guild killing at a level sufficient to cause a decline in numbers. 
Disease

314 Following otter recovery, body condition of mink in the Upper Thames appeared to have

315 declined (Harrington et al. 2009b). No up-to-date information is available but, if a decline in

316 body condition has occurred, further consequences, such as increased susceptibility to

317 disease and/or reduced reproductive success, are possible - either or both of which could potentially lead to population declines.

Farmed mink are susceptible to a range of viruses including Aleutian Mink Disease virus

321 (AMDV), mink enteric virus, canine distemper virus (CDV) and influenza A virus (reviewed in Newman and Byrne 2017). AMDV is a highly contagious parvovirus that can infect all mustelids and cause death within a few months. The virus can be spread in body fluids, as a sexually transmitted disease, and to offspring during pregnancy. Pathogenicity varies (with individual and viral strain), but evidence from fur farms suggest that kit mortality can be very high, and adult females can suffer reduced fertility and abortion. AMDV prevalence among apparently healthy feral mink can be as high as 70\% (Yamaguchi and Macdonald 2001, Harrington et al. 2012b) and antibodies to CDV have been detected in mink and polecats in Spain (Philippa et al. 2008). Wild mink may also be exposed to bacterial and parasitic diseases such as Toxoplasma gondii, Leptospirosis, Cryptosporidium, and Skrjabingylus nasicola (see Newman and Byrne 2017 and references therein). There is little information on the effects of these pathogens on wild mink, and no studies of which we are aware have attempted to relate disease incidence to population status. However, recent findings of increasing parasite abundance in mink over time since colonization and links 

suggest that disease, and its effects, warrant further study.

Anticoagulant rodenticides are used in agricultural and urban rodent control. They act by inhibiting blood clotting such that lethal exposure leads to death by internal hemorrhaging

342 (Lefebvre et al. 2017). Secondary poisoning occurs when a predator ingests poisoned prey, and is a conservation concern for a number of native protected predators that feed on rodents, in Britain (e.g. red kites Milvus milvus Walker et al. 2010) and elsewhere (e.g. European mink Mustela lutreola in Spain, Fournier-Chambrillon et al. 2004). Second generation anticoagulant rodenticide (SGAR) residues were detected in $79 \%$ of 68 road-kill polecat carcasses tested, and the rate of detection since the 1990s had almost doubled in

348 line with a moderate nationwide increase in SAGR usage (Sainsbury et al. 2018). Similarly, 79\% of 99 mink trapped in Scotland had detectable residues of at least one anticoagulant rodenticide, and over $50 \%$ of positive animals had residues of two or more (Ruiz-Suarez et farms than for those in low density farming areas. There appear to be few up-to-date data on national-level rodenticide usage (although annual monitoring of non-target exposure using the barn owl as an indicator species is carried out under the UK's Rodenticides Stewardship Scheme, Rodenticides Stewardship Government Oversight Group 2019), and little broad understanding of the implications of exposure to animal health. That polecats have undergone a considerable population recovery despite increasing exposure to anticoagulant rodenticides suggest that rodenticide poisoning alone is unlikely to have 
caused a decline in mink populations, but it may have more subtle effects that act in concert with other stressors. Kean et al. (2013), for example, caution that newer aquatic pollutants (particularly those with endocrine-disrupting properties), and their impacts on semi-aquatic predators, should be monitored.

\section{Culling}

Two landscape-scale mink control projects (one in Scotland and one in England) provide evidence of an impact of culling on mainland mink populations. The Scottish Mink Initiative (SMI) was centred in the Cairngorms National Park, and began in the headwaters of river catchments, gradually progressing downstream with the aim of creating refuges for water voles (Bryce et al. 2011). Between 2006 and 2009 the project removed 376 mink (47\% of which were females) and successfully eradicated breeding mink from an area of $10,570 \mathrm{~km}^{2}$ (Bryce et al. 2011; mink captured per km of waterway were reduced from 0.16 to 0.06 to 0.01 in the first, second and third years of the project, Oliver et al. 2016). The project has now expanded across the north and east of Scotland, managed largely by local NGOs, working over an area of $29,000 \mathrm{~km}^{2}$ (Fraser et al. 2017). Across this area relative mink density was estimated to have been reduced to $<20 \%$ of the predicted maximum, after 6 years of control (Melero et al. 2015). In England, the area covered by the Eastern Region Mink and Water Vole Project has been expanding continuously since 2001. Mink control and monitoring efforts are (at the time of writing) coordinated across nine counties including three (Norfolk, Suffolk and Essex) that are part of the Eastern Region Mink Database (managed by Norfolk County Council and the Essex and Suffolk Wildlife Trusts, respectively), covering an area of $26,000 \mathrm{~km}^{2}$. Data from Norfolk provide evidence of local mink declines 
(c. $90 \%$ decline in annual numbers trapped) on catchments where trapping effort has been consistent and on-going for 10 years or more (Pyatt 2017). However, not all catchments have seen a decline (see Pyatt 2017) and anecdotal reports from other regions of England where culling has been piecemeal suggest that mink remain abundant there (D. Tansley, unpub. data.). The ineffectiveness of culling in these areas is presumably due to insufficient effort (in intensity, duration or scale). The SMI was the largest mainland invasive species eradication effort worldwide (Bryce et al. 2011) and its success was largely due to the scale of the project (which reduced re-colonization risk, Fraser et al. 2017), helped by the naturally low densities of mink in the upland regions of the project area (Bryce et al. 2011).

Given that the SMI covers more than a third of the area of Scotland, we might expect an overall decline in the distribution and abundance of mink across Scotland, the extent of which would be dependent on the rate of influx from surrounding areas into the removal area (see Oliver et al. 2016), and on-going colonization of the northern Highlands (above). each project differs (in space and time). Individual projects are typically confined to specific areas or catchments, usually attached to short term (3-5 year) funding, and subject to variable effort. Currently, therefore, our ability to assess the wider impact of culling across Britain as a whole is limited.

402

\section{Conclusion}

405 A recent review of the population and conservation status of British mammals estimates mink to number approximately 122,000 (Mathews et al. 2018). Using $95 \%$ confidence 
407

408

409

410

411

412

413

414

415

416

417

418

419

420

421

422

423

424

425

426

427

428

429

intervals given for mink density in Harrington et al. (2009b) suggests a population between approximately 90,000 and 180,000 (based on a density of $0.45-0.90$ mink per $\mathrm{km}$, and 0.74 occupancy as in Bonesi et al. 2006). However, and in accordance with Mathews et al. (2018), the quality of this estimate is low since it is based on national-level occupancy estimates derived from scat surveys, which, we argue, are unreliable.

We conclude that, at a national level, it is not possible, on the basis of currently available data, to ascertain the current status of mink or assess the underlying trend in their population, due to deficiencies in all national-level available datasets. There is evidence of declines in some regions due to culling: notably, the Scottish Highlands (Bryce et al. 2011), and perhaps others in England (above). At a national level, therefore, mink distribution could be surmised to have declined, if mink could be assumed to be absent from these regions; it is more likely, however, that continual immigrant pressure results in a very low density of individual transient mink (Harrington et al. 2009a, Oliver et al. 2016). On this basis, we suggest that mink in Britain likely have a patchy distribution, with areas of low abundance. Ongoing colonization in the far north of Scotland (Harrington et al. 2010, Fraser et al. 2017) means that distributional limits are fluid, and that distribution may even increase. Elsewhere (outside effective control regions) abundance is unknown. Certainly there are areas where mink remain abundant or appear to be increasing (D. Tansley, unpub. data) but there are others where evidence suggests that mink have declined but trapping effort is low (e.g. Devon and Cornwall, K. Hills, pers. comm.) and the cause of the decline unknown. 
430 If mink have declined more widely, rodenticides might be an overlooked cause of decline

431 (see e.g. Ruiz-Suarez et al. 2016) and the role of infectious disease and other health-related

432 conditions (Harrington et al. 2012) in mink population dynamics warrants further attention.

433 It is also possible that mink populations in Britain exhibited ecological 'overshoot' at their

434 peak, such that the numbers reached post-colonisation exceeded the carrying capacity of

435 local habitats, and reached levels that could not be sustained, any decline observed

436 thereafter reflecting a return to a sustainable population size. This phenomenon has been

437 observed in other invasive species (e.g. Simberloff and Gibbons 2004). Conversely, although

438 competitive interactions likely occur among mink and native competitors, there is no robust

439 evidence that recovering otter populations have caused a decline in mink populations.

In addition to information on mink numbers and temporal trends, comparable spatial data are needed to allow analysis of potential causes of change. Currently, there are three significant problems: national-level occupancy data are potentially flawed, they are $10-15$ years out of date (during a period when culling efforts in some areas have intensified), and, where potentially insightful regional-level data exist, there are no spatial comparisons.

Recommendations for future monitoring

A good monitoring program requires standardized and repeatable methodology to allow replication over a large scale, in different habitats, and repeat surveys over time. Sufficient precision is needed to allow detection of change, and sufficient practicality to ensure it is feasible over the required scale. In the absence of dedicated funding, alternative data sources, where effort can be accounted for, can be invaluable. For mink in Britain, data from 
454

455

456

457

458

459

460

461

462

463

464

465

466

467

468

469

470

471

472

473

474

475

476

additional mink hound packs (Bailey's Hunting Directory lists 22 still active,

www.bailyshuntingdirectory.com) would be useful to assess regional variation in population trends and identify causes. These data were instrumental in identifying and pinpointing the cause of the otter decline in the 1960s (Chanin and Jefferies 1978). Useful data could be obtained from mink control projects if they recorded, at a minimum, the numbers of mink captured per km of river trapped, trapping effort, and duration (see e.g. Oliver 2015).

Alternative, potentially low cost, methods (such as eDNA, e.g. Rees et al. 2014, see also

McDevitt et al. 2020 and references therein), that could provide data on several aquatic and semi-aquatic species simultaneously, might also be useful, and should be explored. In all of these, the key will be standard recording protocols, accessibility and data sharing.

\section{Management of mink in Britain}

Knowing how many mink there are in Britain, and understanding their (potentially changing) status, is not just an academic pursuit. Successful water vole restoration, for example, depends on effective mink removal (Moorhouse et al. 2015), which, in turn, depends on careful assessment of 'effectiveness', which is dependent on on-going accurate monitoring of mink abundance, and immigration rates. False perceptions of declining mink populations, at local, regional or national, scales, lead to complacency, and risk ineffective protection of native biodiversity. Continual monitoring of the numbers removed, but most importantly the impact of removals on long-term population size, is crucial for ensuring that the numbers of individual mink killed are minimized (for ethical reasons) and that management strategies conform to best possible practice. 
478

479

480

481

482

Invasive mink impact native biodiversity across Europe. Eradication at any scale would be an enormous undertaking but relatively easier for Britain, which does not have fur farms (a continual source of escapees), and is protected from further invasion from the mainland by being an island. Whilst there are a number of organizations in Britain undertaking mink control, these efforts need joined up, national-level thinking (see for example Martin and Lea 2020), combined with a long-term strategy towards an agreed, and clearly stated, outcome, together with long-term funding and commitment to monitoring.

Management of mink is a policy decision (not a biological decision), based on what people want: where mink can be tolerated, where they cannot be tolerated, and where and how they can be removed, with respect to cost, effectiveness and animal welfare. All of these considerations require robust, accurate biological data on spatial distribution and abundance, which, as we have shown, are currently lacking. Collaboration, coordination, and record keeping (and sharing) are required, as well as attention to proper interpretation of existing data, and the use of alternative potentially insightful data sources. In short: we can, and should, do better.

\section{Acknowledgements}

This review was supported by South West Water. We thank Kate Hills for encouraging the work, Mark Prout for provision of the mink hunt data, and Andrew Harrington and Andy Rothwell for comments on an earlier draft.

\section{References}


Aebischer NJ, Davey PD, Kingdon NG (2011) National Gamebag Census: Mammal Trends to

2009. Game \& Wildlife Conservation Trust, Fordingbridge.

504

http://www.gwct.org.uk/ngcmammals

505

506

Barrientos R (2015) Adult sex-ratio distortion in the native European polecat is related to

the expansion of the invasive American mink. Biological Conservation 186: 28-34.

508

Birks JDS, Kitchener AC (1999) The distribution and status of the polecat Mustela putorius in

Britain in the 1990s. The Vincent Wildlife Trust, London.

511

Birks J, Messenger J, Braithwaite T, Davison A, Brookes R, Strachan C (2004) Are scat surveys

a reliable method for assessing distribution and population status of pine martens? In:

Harrison DJ, Fuller AR, Proulx G (eds) Martens and fishers in human-altered environments.

Springer, New York.

516

517 Bonesi L, Macdonald DW (2004) Impact of released Eurasian otters on a population of

518 American mink: a test using an experimental approach. Oikos 106: 9-18.

Bonesi L, Strachan R, Macdonald DW (2006) Why are there fewer signs of mink in England?

521 Considering multiple hypotheses. Biological Conservation 130: 268-277.

523 Bonesi L, Dunstone N, O'Connell M (2000) Winter selection of habitats within intertidal 
526 Bryce R, Oliver MK, Davies L, Gray H, Urquhart J, Lambin X (2011) Turning back the tide of

527 American mink invasion at an unprecedented scale through community participation and

528 adaptive management. Biological Conservation 144:575-83.

529

530 Chanin P (2013) Otters. Whittet Books, Essex

531

532 Chanin PRF, Jefferies DJ (1978) The decline of the otter Lutra lutra L. in Britain: an analysis of 533 hunting records and discussion of causes. Biological Journal of the LInnean Society 10: 305534328.

535

536 Corbet GB (1971) Provisional distribution maps of British mammals. Mammal Review 1: 95537142.

538

539 Craik JCA (2008) Sex ratio in catches of American mink - How to catch the females. Journal 540 for Nature Conservation 16:56-60.

541

542 Craik JCA (1997) Long term effects of North American mink Mustela vison on seabirds in

543 Western Scotland. Bird Study 44: 303-09.

544

545 Crawford A (2003) Fourth otter survey of England 2000-2001. Environment Agency, Bristol.

546

547 Crawford A (2010) Fifth otter survey of England 2009-2010. Environment Agency, Bristol 
Croose E (2016) The Distribution and Status of the Polecat Mustela putorius in Britain 20142015. Vincent Wildlife Trust, Ledbury, UK.

551

552 Cuthbert JH (1973) The origin and distribution of feral mink in Scotland. Mammal Review 3:

553 97-103.

554

555

Dunstone N (1993) The mink. T \& AD Poyser Ltd, London.

556

557 Fournier-Chambrillon C, Berny PJ, Coiffier O, Barbedienne P, Dassé B, Delas G, et al. (2004)

558 Evidence of secondary poisoning of free-ranging riparian mustelids by anticoagulant

559 rodenticides in France: implications for conservation of European mink (Mustela lutreola).

560 Journal of Wildlife Diseases 40: 688-695.

561

562 Fraser EJ, Harrington LA, Macdonald DW, Lambin X (2017) Control of an invasive species: the

563 American mink in Great Britain In: Macdonald DW, Newman C, Harrington LA (eds) Biology

564 and Conservation of Musteloids, 357-369. Oxford University Press, Oxford

565

566 Genovesi P, Carnevali L, Alonzi A, Scalera R (2012) Alien mammals in Europe: updated

567 numbers and trends, and assessment of the effects on biodiversity. Integrative Zoology 7:

$568 \quad 247-253$.

569

570 Harrington LA, Macdonald DW (2008) Spatial and temporal relationships between invasive

571 American mink and native European polecats in the southern United Kingdom. Journal of

572 Mammalogy 89: 991-1000. 
573

574 Harrington LA, Macdonald DW (2015) Riparian mustelids in the Upper Thames: a case of

575 alien invasives versus native competitors. In: Macdonald DW, Feber R (eds) Farming and

576 Wildlife. Conflict in the countryside, 148-164. Oxford University Press, Oxford.

577

578 Harrington LA, Harrington AL, Hughes J, Stirling D, Macdonald DW (2010) The accuracy of

579 scat identification in distribution surveys: American mink in the northern highlands of

580 Scotland European. Journal of Wildlife Research 56: 377-384.

581

582

Harrington LA, Harrington AL, Moorhouse T, Gelling M, Bonesi L, Macdonald

DW (2009a) American mink control on inland rivers in southern England: an experimental

test of a model strategy. Biological Conservation 142: 839-849.

585

586

Harrington LA, Harrington AL, Yamaguchi N, Thom M, Ferreras P, Windham TR, Macdonald

587

DW (2009b) The impact of native competitors on an alien invasive: temporal niche shifts to avoid inter-specific aggression? Ecology 90: 1207-1216.

589

590 Harrington LA, Harrington AL, Macdonald DW (2008) Distinguishing the tracks of mink 
596

597

598

599

600

601

602

603

604

605

606

607

608

609

610

611

612

613

614

615

616

617

618

619

Jefferies DJ (2003) The water vole and mink survey of Britain 1996-1998 with a history of the

long-term changes in the status of both species and their causes. The Vincent Wildlife Trust, Ledbury.

Kean EF, Lyons G, Chadwick EA (2013) Persistent organic pollutants and indicators of otter health. A CHEM Trust report.

Kolodziej-Sobocinska M, Brzezinski M, Niemczynowicz A, Zalewski A (2018) High parasite infection level in non-native invasive species: it is just a matter of time. Ecography 41: 12831294.

Lefebvre S, Fourel I, Queffélec S, Vodovar D, Mégarbane B, Benoit E, Siguret V, Lattard V (2017) Poisoning by Anticoagulant Rodenticides in Humans and Animals: Causes and Consequences. In: Malangu N (ed) Poisoning. IntechOpen www.intechopen.com

Linn IJ and Stevenson JHF (1980) Feral mink in Devon. Nature in Devon 1:7-27.

Macdonald DW, Harrington LA (2003) The American mink: the triumph and tragedy of adaptation out of context. New Zealand Journal of Zoology 30: 421-441.

Macdonald DW, Harrington LA, Yamaguchi N, Thom MD, Bagniewska J (2015) Biology, ecology and reproduction of American mink, Neovison vison, on lowland farmland. In: Macdonald DW, Feber R (eds) Farming and Wildlife. Conflict in the countryside, 126147. Oxford University Press, Oxford. 
620

621 Martin AR, Lea VJ (2020) A mink-free GB: perspectives on eradicating American mink

622 Neovison vison from Great Britain and its islands. Mammal Review 50: in press.

623

624 Mathews F, Kubasiewicz LM, Gurnell J, Harrower CA, McDonald RA, Shore RF (2018) A

625 Review of the Population and Conservation Status of British Mammals: Technical Summary.

626 Natural England, Peterborough.

627

628

McDevitt A, Browett S, O'Meara D (2020) The application of genetic and genomic tools for

629

invasive species management in mammals: recent trends and future perspectives. Mammal

630 Review 50: in press.

631

632

McDonald RA, Harris S (1999) The use of trapping records to monitor populations of stoats

633 Mustela erminea and weasels M. nivalis: the importance of trapping effort. Journal of

634 Applied Ecology 36: 679-688.

635

636

Melero Y, Robinson E, Lambin X (2015) Density- and age-dependent reproduction partially

637 compensates culling efforts of invasive non-native American mink. Biological Invasions

638 $17: 2645-57$.

639

640 Melero Y, Palazón S, Lambin X (2014) Invasive crayfish reduce food limitation of alien

641 American mink and increase their resilience to control. Oecologia 174:427-34. 
643 Moore NP, Roy SS, Helyar A (2003) Mink (Mustela vison) eradication to protect ground-

644 nesting birds in the Western Isles, Scotland, United Kingdom. New Zealand Journal of

645 Zoology 30: 443-452.

646

647 Moorhouse TP, Macdonald DW, Strachan R, Xavier L (2015) What does conservation

648 research do, when should it stop, and what do we do then? Questions answered with water

649 voles. In: Macdonald DW, Feber R (eds) Farming and Wildlife. Managing for nature on

650 lowland farms, pp. 269-290. Oxford University Press, Oxford.

651

652 Nentwig W, Bacher S, Kumschick S, Pyšek P, Vilà M (2018) More than "100 worst" alien

653 species in Europe. Biological Invasions 20:1611-21.

654

655 Newman C, Byrne AW (2017) Musteloid diseases: implications for conservation and species

656 management. In: Macdonald DW, Newman C, Harrington LA (eds) Biology and Conservation

657 of Musteloids, 231-254. Oxford University Press, Oxford

658

659 Oliver M (2015) A review of large-scale coordinated mink control in Scotland 2006-2015.

660 RAFTS https://www.invasivespecies.scot/american-mink-0

661

662 Oliver MK, Piertney SB, Zalewski A, Melero Y, Lambin X (2016) The compensatory potential

663 of increased immigration following intensive American mink population control is diluted by

664 male-biased dispersal. Biological Invasions 18:3047-61.

665 
666 Philippa J, Fournier-Chambrillon C, Fournier P, Schaftenaar W, van de Bildt M, van

667 Herweijnen R, et al. (2008) Serologic survey for selected viral pathogens in free-ranging

668 endangered European mink (Mustela lutreola) and other mustelids from south-western

669 France. Journal of Wildlife Diseases 44: 791-801.

670

671 Podrá M, Gómez A (2018) Rapid expansion of the American mink poses a serious threat to 672 the European mink in Spain. Mammalia 82: 580-588.

673

674 Pyatt C (2017) Clearing the way for Norfolk's water voles: an analysis of the Norfolk Mink 675 Control Project (up to end 2016). The Norfolk Mink Project. Available from

676 https://thenorfolkminkproject.org.uk

677

678 Rees HC, Maddison BC, Middleditch DJ, Patmore JR, Gough KC (2014) REVIEW: The

679 detection of aquatic animal species using environmental DNA - a review of eDNA as a

680 survey tool in ecology. Journal of Applied Ecology 51: 1450-1459.

681

682

Roberts SC, Gosling LM, Thornton EA, McClung J (2001) Scent-marking by male mice under 683 the risk of predation. Behavioural Ecology 12: 698-705.

684

685

Rodenticides Stewardship Government Oversight Group (2019) Report on the Rodenticides

686

Stewardship Regime. Assessment of Implementation-January 2019.

687 http://www.hse.gov.uk/biocides/eu-bpr/Rodenticides-Stewardship-Regime-GOG-rev-

688 Feb2019.pdf 
690 Rodrigues DC, Simoes LC, Mullins J, Lampa S, Mendes RC, Fernandes C, Rebelo R, Santos691 Reis M (2015) Tracking the expansion of the American mink (Neovison vison) range in NW 692 Portugal. Biological Invasions 17: 13-22.

693

694 Rothman RJ, Mech LD (1979) Scent-marking in lone wolves and newly formed pairs. Animal 695 Behaviour 27: 750-760.

696

697 Ruiz-Olmo J, Palazon S, Bueno F, Bravo C, Munilla I, Romero R (1997) Distribution, status and 698 colonization of the American mink Mustela vison in Spain. Journal of Wildlife Research 2:30699 36.

700

701

Ruiz Suárez N, Melero Y, Giela A, Henríquez-Hernández LA, Sharp E, Boada LD et al. (2016).

Rate of exposure of a sentinel species, invasive American mink (Neovison vison) in Scotland, to anticoagulant rodenticides. Science of the Total Environment 569.

704

Sainsbury KA, Shore RF, Schofield H, Croose E, Campbell RD, McDonald RA (2019) Recent

706 history, current status, conservation and management of native mammalian carnivore species in Great Britain. Mammal Review 49: 171-188

708

709 Sainsbury KA, Shore RF, Schofield H, Croose E, Pereira MG, Sleep D, Kitchener AC, Hantke G, McDonald RA (2018) Long-term increase in secondary exposure to anticoagulant

711 rodenticides in European polecats Mustela putorius in Great Britain. Environmental Pollution 236: 689-698. 
713 Sidorovich V, Macdonald DW (2001) Density dynamics and changes in habitat use by the

714 European mink and other native mustelids in connection with the American mink expansion

715 in Belarus. Netherlands Journal of Zoology 51: 107-126

716

717 Sidorovich VE, Kruuk H, Macdonald DW (1999) Body size, and interactions between

718 European and American mink (Mustela lutreola and M. vison) in Eastern Europe. Journal of

719 Zoology 248: 521-527.

720

721 Simberloff D, Gibbons L (2004) Now you see them, now you don't! - population crashes of established introduced species. Biological Invasions 6: 161-172.

723

Simpson V (2006) Patterns and significance of bite wounds in Eurasian otters (Lutra Lutra) in 725 southern and south-west England. The Veterinary record 158: 113-119.

726

727

SNH (2018) Birds flock back to 'mink free' Hebrides. 10 July 2018,

https://www.snhpresscentre.com/news/birds-flock-back-to-mink-free-hebrides

729

730 Strachan R (2007) National survey of otter Lutra lutra distribution in Scotland 2003-04.

731

Scottish Natural Heritage Commissioned Report No. 211.

732

733

Strachan R, Jefferies DJ (1993) The water vole Arvicola terrestris in Britain 1989-1990: its distribution and changing status. The Vincent Wildlife Trust, London. 
Strachan R, Jefferies DJ (1996) Otter survey of England 1991-1994. The Vincent Wildlife

737

738

739

740

741

742

743

744

745

746

747

748

749

750

\section{Figure Legends}

752

753

754

755

756

757

758 surveys (see text).

Thompson H (1968) British wild mink. Annals of Applied Biology 61: 345-349.

Walker LA, Lawlor AJ, Llewellyn NR, Pereira MG, Potter ED, Molenaar FM, Sainsbury AW, Shore RF (2010) Anticoagulant rodenticides in predatory birds 2007 \& 2008: a Predatory Bird Monitoring Scheme (PBMS) report. Centre for Ecology \& Hydrology, Lancaster, UK.

Yamaguchi N, Macdonald DW (2001) Detection of Aleutian disease antibodies in feral American mink in southern England. The Veterinary Record 149: 485-488.

Yamaguchi N, Rushton SP, Macdonald DW (2003) Habitat preferences of feral American mink in the Upper Thames. Journal of Mammalogy 84:1356-73.

Fig 1. Percentage occupation of $10 \mathrm{~km}$ survey squares by feral mink in western and eastern England, Wales and mainland Scotland south of the Great Glen, 1955 to 1997. Redrawn from Jefferies (2003), with kind permission from VWT.

Fig 2. Number of mink-positive hectads (10 x 10km squares) as reported in England otter

Fig 3. Mink scats ( $\% 500 \mathrm{~m}$ rivers sections in which one or more scats were detected, $n=36$ ) and tracks (\% rafts with tracks, $n=20$ ) on the $\mathrm{R}$ Cherwell in southern England, following 
759 colonization of the river by otters in summer/autumn 2004. J=July, S=September,

$760 \mathrm{~N}=$ November, $\mathrm{M}=$ March, $\mathrm{XX}=$ year. Redrawn using data in Harrington and Macdonald (2015).

761 Fig 4. National game bag index for mink, 1962-2009. Error bars are 95\% confidence

762 intervals. Data from Aeibsicher et al. (2011). http://www.gwct.org.uk/ngcmammals.

763 Accessed August 2019.

764 Fig 5. Number of records of mink presence per year held by the NBN, 1950-2015, for

765 England (a), Scotland (b) and Wales (c), the dotted lines indicating a 5-year moving average, 766 and (d) the distribution of NBN mink records in 2010. The circles in d show the location of

767 local mink control projects illustrating the likely influence of local interest on recorder

768 effort. Data source: NBN Atlas website,

769 http://www.nbnatlas.org https://species.nbnatlas.org/species/NHMSYS0020774297.

770 Accessed August 2018. Note that the NBN Trust, and the listed Data Partners, bear no

771 responsibility for any further analysis or interpretation of the data presented here.

772 Fig 6. Number of mink found, and killed, per day by the Devon and Cornwall minkhounds,

$7731976-2015$. Data courtesy of M. Prout. 


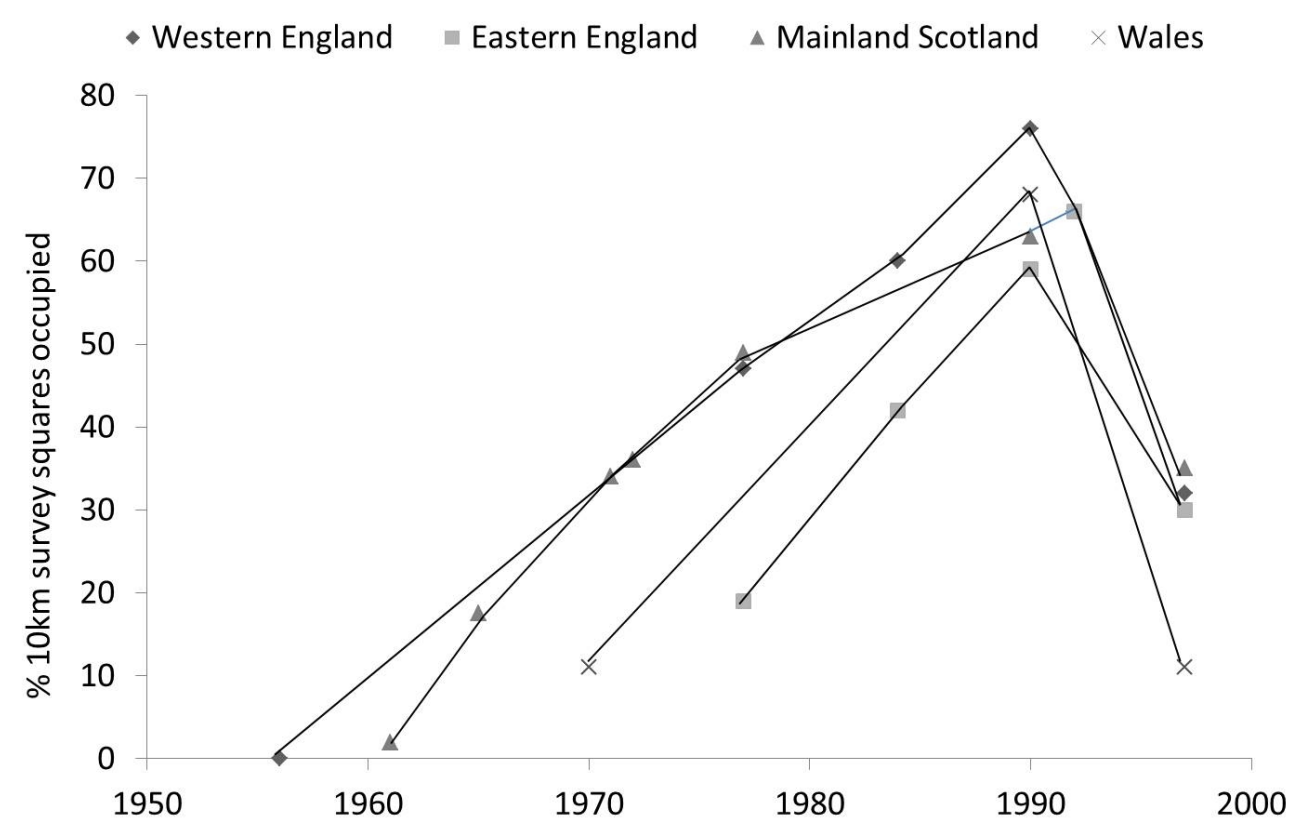

Fig. 1. Percentage occupation of $10 \mathrm{~km}$ survey squares by feral mink in western and eastern England, Wales and mainland Scotland south of the Great Glen, 1955 to 1997. Redrawn from Jefferies (2003), with kind permission from VWT.

$237 \times 152 \mathrm{~mm}(150 \times 150 \mathrm{DPI})$ 


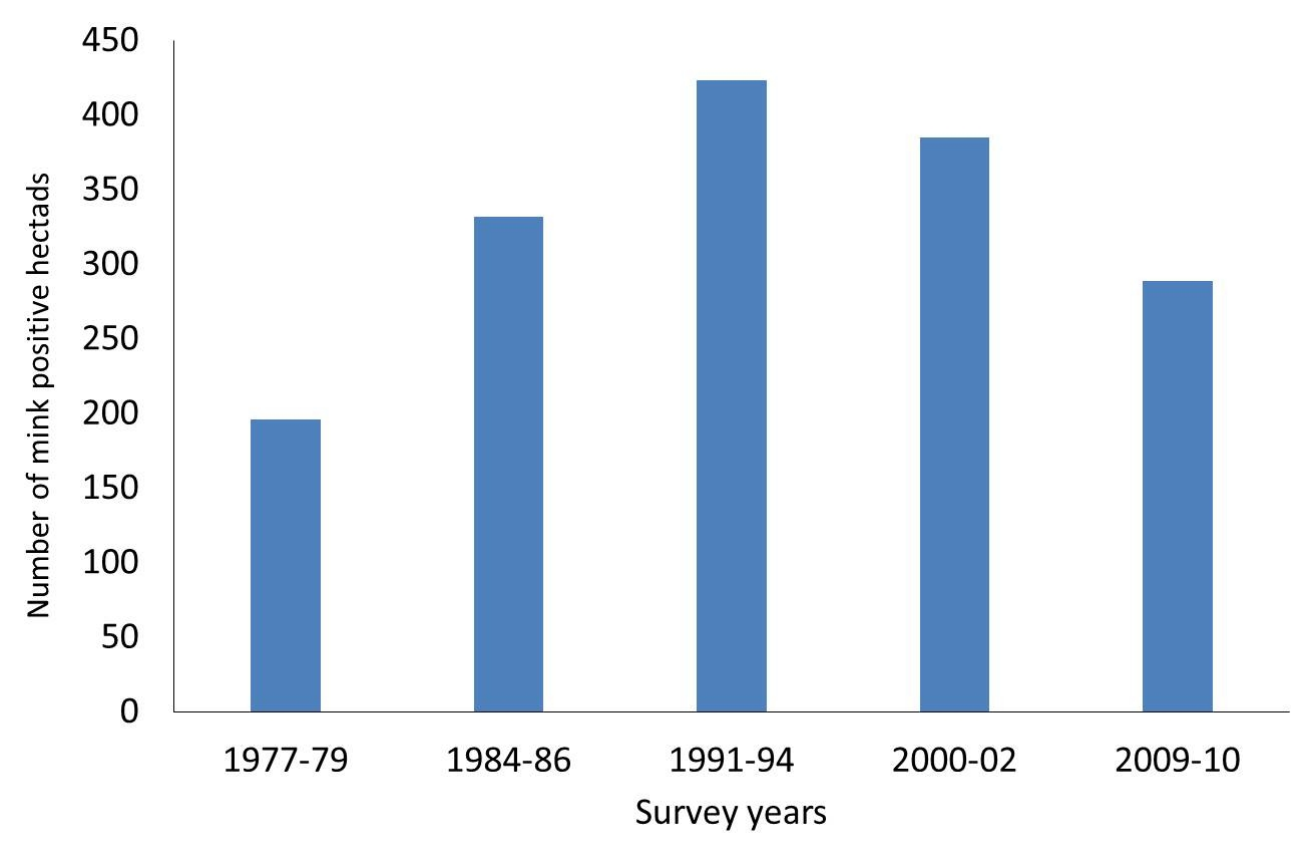

Fig. 2. Number of mink-positive hectads (10 $\times 10 \mathrm{~km}$ squares) as reported in England otter surveys (see text).

$220 \times 143 \mathrm{~mm}(150 \times 150 \mathrm{DPI})$ 


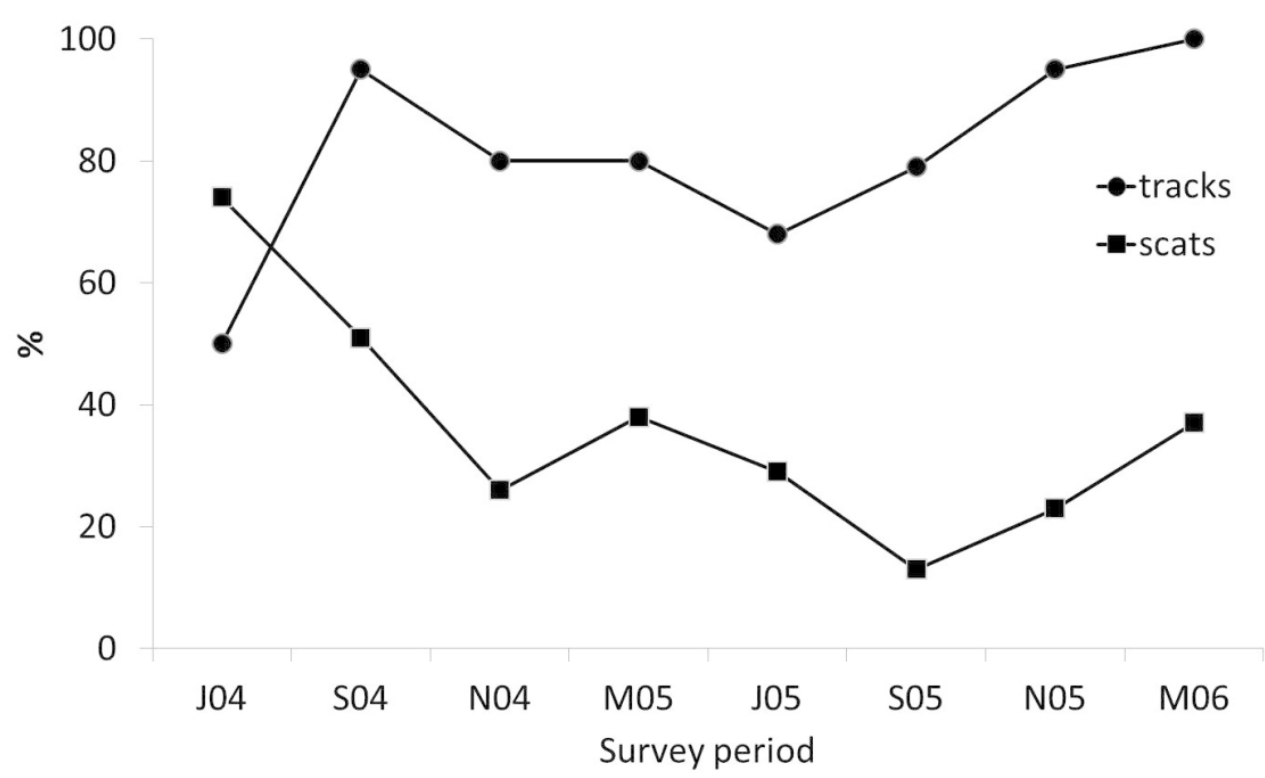

Fig. 3. Mink scats ( $\% 500 \mathrm{~m}$ rivers sections in which one or more scats were detected, $\mathrm{n}=36$ ) and tracks (\% rafts with tracks, $\mathrm{n}=20$ ) on the $\mathrm{R}$ Cherwell in southern England, following colonization of the river by otters in summer/autumn 2004. J=July, $\mathrm{S}=$ September, $\mathrm{N}=$ November, $\mathrm{M}=$ March, $\mathrm{XX}=$ year. Redrawn using data in Harrington and Macdonald (2015).

$239 \times 145 \mathrm{~mm}(150 \times 150 \mathrm{DPI})$ 


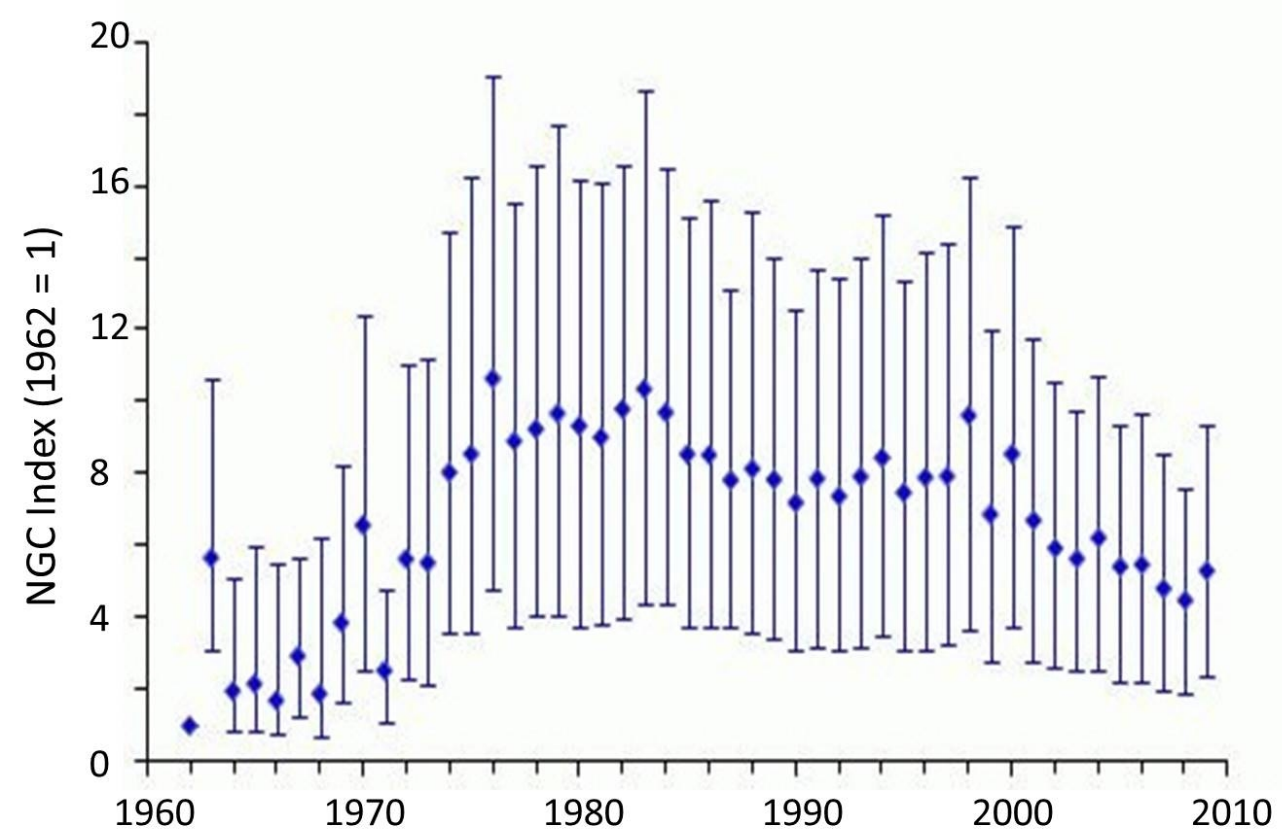

Fig. 4. National game bag index for mink, 1962-2009. Error bars are $95 \%$ confidence intervals. Data from Aeibsicher et al. (2011). http://www.gwct.org.uk/ngcmammals. Accessed August 2019. 

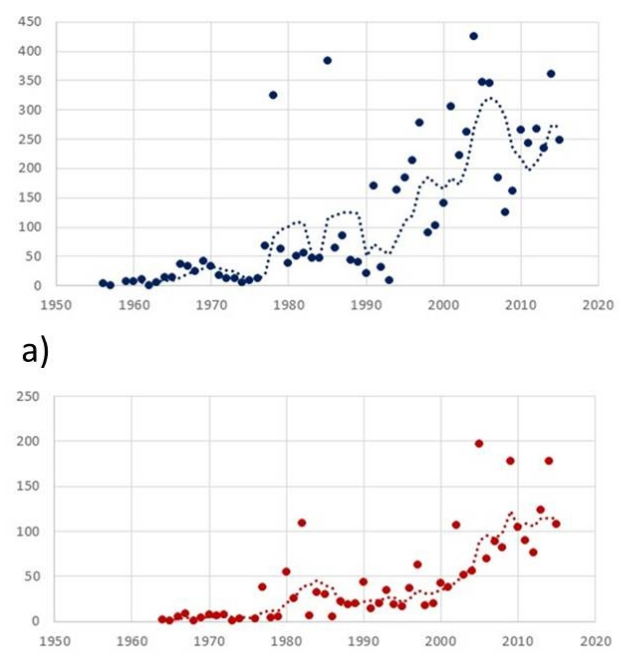

b)

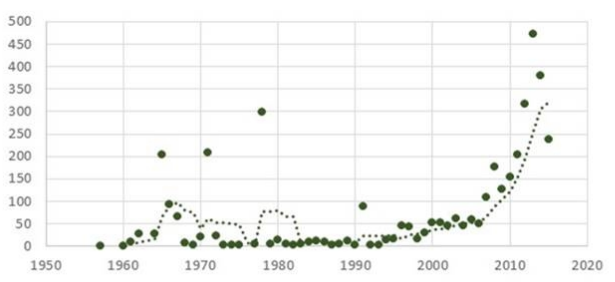

d)

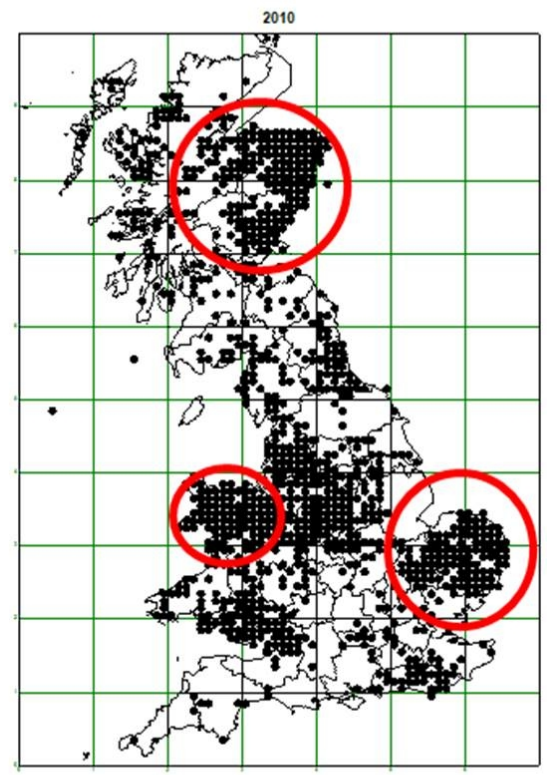

c)

Fig 5. Number of records of mink presence per year held by the NBN, 1950-2015, for England (a), Scotland (b) and Wales (c), the dotted lines indicating a 5-year moving average, and (d) the distribution of NBN mink records in 2010. The circles in d show the location of local mink control projects illustrating the likely influence of local interest on recorder effort. Data source: NBN Atlas website, http://www.nbnatlas.org https://species.nbnatlas.org/species/NHMSYS0020774297. Accessed August 2018. Note that the NBN Trust, and the listed Data Partners, bear no responsibility for any further analysis or interpretation of the data presented here.

$221 \times 182 \mathrm{~mm}(150 \times 150 \mathrm{DPI})$ 


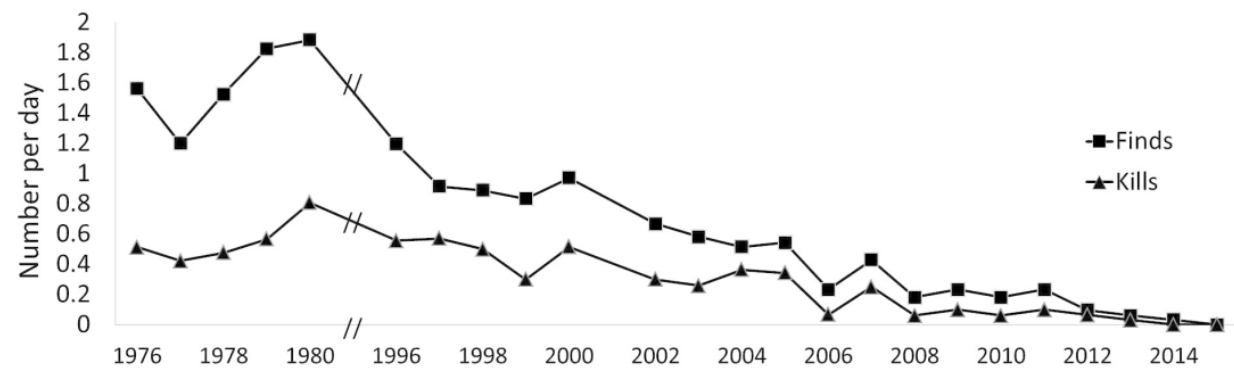

Fig. 6. Number of mink found, and number killed, per day by the Devon and Cornwall minkhounds, 1976 2015. Data courtesy of M. Prout.

$338 \times 139 \mathrm{~mm}(150 \times 150 \mathrm{DPI})$ 